\title{
Assessment of the Implicit Attitude of Japanese People toward Blacks and Little Black Sambo
}

\author{
Kazuo Mori \\ Matsumoto University, Matsumoto, Japan \\ Email: kazuo.mori@t.matsu.ac.jp
}

How to cite this paper: Mori, K. (2018) Assessment of the Implicit Attitude of Japanese People toward Blacks and Little Black Sambo. Open Journal of Social Sciences, 6, 1-13. https://doi.org/10.4236/jss.2018.61001

Received: December 5, 2017

Accepted: January 5, 2018

Published: January 8, 2018

Copyright (C) 2018 by author and Scientific Research Publishing Inc. This work is licensed under the Creative Commons Attribution International License (CC BY 4.0).

http://creativecommons.org/licenses/by/4.0/

\section{(c) (i) Open Access}

\begin{abstract}
We examined whether Japanese people, 47 junior high school students, 49 undergraduates, and 52 older adults, possessed negative attitudes against blacks and the picture book Little Black Sambo. We assessed the implicit attitude toward the target word pairs, "black/white" and "Sambo/Heidi," by utilizing a paper-based Implicit Association Test and found that both black and Sambo were associated more negatively than white and Heidi. However, the implicit attitudes assessed with a single-target IAT showed that 67 Japanese students showed positive implicit scores for blacks but with smaller valences. A post hoc analysis revealed that the reading experience of Little Black Sambo did not show a significant difference between the implicit attitudes of those who had and had not read the book.
\end{abstract}

\section{Keywords}

Paper-Based Implicit Association Test, Racial Attitudes, Little Black Sambo, Japanese Adults, Japanese Undergraduates, Japanese Junior High School Students

\section{Introduction}

Helen Bannerman's picture book A Story of Little Black Sambo (LBS) was pulled out of all Japanese bookstores in 1988 after having been alleged of containing racist characteristics, especially in the usage of the word "Sambo" for the protagonist. All the versions of $L B S$ books disappeared from the bookstores not because it was banned but because the publishers autonomously stopped publishing them and withdrew them from the market. The Japanese mass media reported the disappearance of the book being alleged its racist characteristics without further arguments on the issue. The official announcement by the president of Iwanami Publishing, a leading publisher in Japan who first published a 
Japanese translation of $L B S$ in Japan in 1956, explained that they found its racist characteristics by an inquiring letter from an anti-racist organization in Osaka, Japan. He did not disclose the details of the racist characteristics. Thus, whether the book really had racist characteristics or not was hardly argued sufficiently in the Japanese mass media (For further details on the issue, see Mori, 2005; 2014) [1] [2].

Meanwhile, there were extensive debates outside of Japan as to whether the book was racist and whether Japanese had discriminated blacks (Russell, 1991; Sircar, 2004; Tajima \& Thornton, 2012) [3] [4] [5]. However, they did not provide objective data based on surveys or research data on this issue. Few surveys or experimental research were conducted by Japanese scholars on this issue either. The Japanese research database, the CiNii Articles (http://ci.nii.ac.jp/), showed 55 studies with the search keyword "Little Black Sambo," but none of them reported objective data from surveys or experiments. One of the crucial reasons why practically no research was attempted was the difficulty of proving or disproving the presence of racism objectively. For example, it is hard to prove the presence of any racist attitudes using conventional research tools, such as questionnaires, because the answers to the questionnaire are likely to be biased from the standpoint of social desirability (DeMaio, 1984) [6]. Respondents can easily tell lies on a questionnaire. Therefore, the questionnaire study could not provide any evidence as to the presence of racism.

The issues related to racial discrimination have been rigorously studied in social psychology. They noticed the inappropriateness of questionnaires and developed various alternative assessment procedures (Greenwald \& Banaji, 1995) [7]. Greenwald and Banaji argued that social behavior, such as racial discrimination and stereotypes, would operate in an implicit or unconscious way so that it could be assessed only with indirect measures such as priming that cognitive psychologists studied in a variety of ways (Fazio, Jackson, Dunton, \& Williams, 1995; Greenwald, McGhee, \& Schwartz, 1998; Wittenbrink, Judd, \& Park, 1997) [8] [9] [10].

Greenwald, McGhee, and Schwartz (1998) [9] invented an implicit measure called the Implicit Association Test (IAT). The IAT comprises a combination of classifying tasks on a computer. The basic IAT procedure is a simple classification task of pleasant and unpleasant words. A participant classifies a series of words presented on the computer screen one by one whether it is pleasant or unpleasant by pressing the designated keys as quickly as possible. In the crucial trials, the participant is presented pairs of target concepts (e.g., "blacks" and "whites" or photos depicting them) interspersed among the pleasant and unpleasant words and required to classify them one way or the other way with the pleasant/unpleasant words; "pleasant" and "blacks" with the left key and "unpleasant" and "whites" with the right key in one task and the reversed combinations in the other. If a participant has a positive implicit attitude toward one of the target pair, the response time will be shorter when the target and the pleasant 
words are assigned to the same response key than the reversed assignment. In this way, the researchers can assess the implicit attitudes toward the target concepts by measuring the difference of the average response times between two tasks of the participant. Soon after the introduction of the IAT, it became widely used in a variety of research areas of social psychology. It has been the representative procedure and most widely used all over the world. McConnell and Leibold (2001) [11] applied the IAT in their research on racial attitudes and concluded that the IAT was suitable for probing racial attitudes without social acceptability biases.

Several researchers tried to develop paper-and-pencil versions of IAT (e.g., Lemm, Lane, Sattler, Khan, \& Nosek, 2008; Lowery, Hardin, \& Sinclair, 2001; Mori, Uchida, \& Imada, 2008; Teachman, Gapinski, Brownell, Rawlins, \& Jeyaram, 2003) [12] [13] [14] [15]. A paper-based IAT would be preferable for researchers to obtain data from a group of participants, in a classroom or lecture hall, where no individual computers are available (Vargas, Sekaquaptewa, \& von Hippel, 2007) [16]. Therefore, the present study aimed to examine whether Japanese people had a negative implicit attitude toward black people by utilizing the paper-based IAT developed by Mori et al. (2008) [14]. We also examined whether the reading experience of $L B S$ had any effect on the racial attitudes of Japanese students.

\section{Assessment of Implicit Attitude toward "Black People," "Sambo," and "Black Hair"}

In the Japanese language, the word referring to the black people is expressed as a combination of two Kanji characters, “黑” and “人”; the former means "black" and the latter "people." Then, even if the IAT scores of the black people is found out to be negative, it may mean the word "black" has a negative connotation, not the "black people" has. Nakayama, Sears, Hino, and Lupker (2014) [17] found that a two-character Kanji compound word had an inhibitory priming effect on the processing another two-character Kanji compound word even though the compound words shared the same initial Kanji. They interpreted this finding as a lexical competition and concluded that the Kanji compound words were processed as whole units rather than separately.

However, the Nakayama et al. study was not based on the IAT assessment. It was not published at the time of the present study either. Therefore, we needed support for applying the IAT assessments using Kanji compound targets. Thus, we included a pair of Kanji compound words "black hair" and "white hair" as target words to serve as a kind of control condition. In Japan, the vast majority of people have black hair that turns white as people get old. Consequently, white hair usually implies being elderly while black hair being young. Therefore, older adults may show a positive implicit attitude toward black hair despite the negative connotation of the word "black." If the results come out as expected, it will assure that the participants have evaluated the target words as a whole rather 
than responding only to its constituent word.

Therefore, we planned to assess the implicit attitudes toward "black/white hair" as well as "black/white people" in three age groups of Japanese people by utilizing the paper-based IAT (Mori et al., 2008) [14]. We also measured the implicit attitude toward "Sambo" paired with "Heidi," a white girl protagonist of a popular TV animation "Heidi, a Girl of the Alps." We chose Heidi because our preliminary assessment had found that all 20 undergraduate students knew the character as well as the story.

\subsection{Method}

Participants. Forty-seven junior high school students (21 boys and 26 girls, 14 - 15 years old), 49 undergraduates and young adults in their twenties (20 males and 29 females, 19 - 29 years old), and 52 adults aged 30 or older (18 males and 34 females, 30 - 67 years old) participated in the study. (The second group was denoted "younger adults" and the third "older adults" in the following.) The education levels of the adult participants were unknown, but they were attendants of an extension course of a university. All of them were native Japanese. The informed-consent procedure was taken explaining to them that the tests would reveal their implicit attitudes and that they could stop participating anytime they wanted to do so, and thus they participated in the measurement voluntarily.

Target words. Three pairs of target words were assessed and compared: black people (黒人) vs. white people (白人), black hair (黒髪) vs. white hair (白髪), and Sambo (サンボ) vs. Heidi (ハイジ).

Construction of the paper-based IAT. Following Mori et al., (2008) [14] three separate booklets were prepared, one for each target pair. Each of the booklets comprised three task sheets: concepts-only task, incongruent task, and congruent task. Each task was printed on a test sheet $(210 \times 297 \mathrm{~mm}$, or A4 size $)$ with 12 rows of six words each (cf., Figure 1). Sixteen pleasant words such as "hope (希望)” and “peace (平和),” and 16 unpleasant words such as “suicide (自殺)” and “danger (危険)” were used as Mori et al. (2008) [14]. (The Kanji shown in parentheses are those actually appeared in the tasks.) As for the "Sambo/Heidi" booklet, all the words were written in three Japanese katakana letters. Each of the pleasant and unpleasant words appeared randomly twice or three times in the Concept-only Task and once or twice in the Congruent/Incongruent Tasks. In accordance with the implicit association tests of Greenwald et al. (1998) [9], "white people/hair" and "Heidi" were included in the pleasant word category and "black people/hair" and "Sambo" in the unpleasant category for the congruent task. In the incongruent task, the target words were assigned to the categories conversely. The target words were randomly interspersed among the concept words, each appearing 16 to 17 times in both the congruent and incongruent task.

Procedure. The assessments were administered group-wise on three different occasions using the test booklets. The three tasks, concepts-only, incongruent, and congruent, were done in this predetermined order throughout the assessments. The instruction for the concept-only task was to draw a circle ("O") on 
pleasant words, and a cross ("X") on unpleasant ones as quickly as possible. In the incongruent tasks, participants were instructed to draw a circle ("O") on "black people/hair" and "Sambo," and a cross ("X") on "white people/hair" and "Heidi." The combinations were reversed on the congruent tasks. Participants were asked to make the classification tasks as quickly as possible in 30 seconds. Please note that, for the paper-based IAT, we measured the amount of performance in the limited time instead of measuring the response times. It took about 15 minutes to complete the entire test session for the three target pairs. We had informed the participants the purpose and characteristics of the IAT beforehand and told them that they could stop participating any time if they wished to do so. As a result, no participants stopped participating in the study.

Questionnaire. Along with the paper-based IAT, a questionnaire was administered to the participants to find out whether they had read $L B S$ or not. The question was a simple yes-or-no type. The participants answered by choosing either "Yes, I have read $L B S$," or "No, I have not read $L B S$."

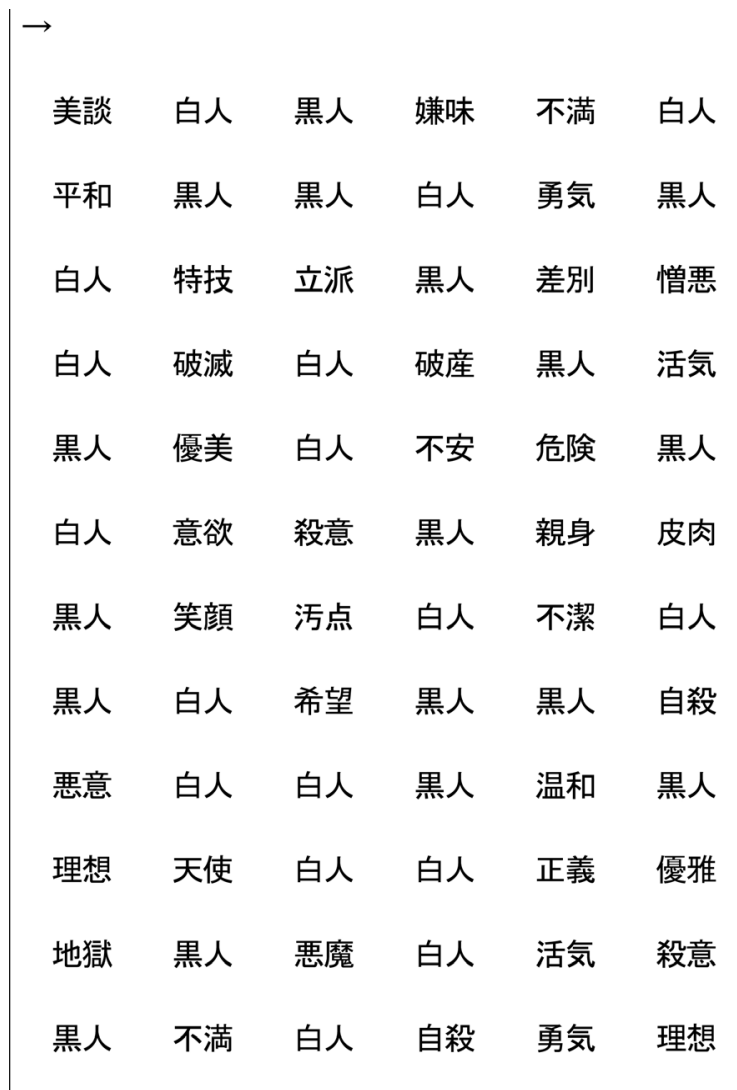

Figure 1. A sample test sheet used for the Congruent/Incongruent Task. The actual sheet was $210 \times 297 \mathrm{~mm}$, or A4 size. The characters were printed in JS Gothic, font size 20 . The instruction for the Congruent Task is as follows: "On the following page, the words 'black people' and 'white people' were printed along with words with positive meaning such as 'success' and 'victory' and those with negative meaning such as 'failure' and 'defeat.' Your task is to mark a circle on 'white people' and the positive words and a cross on 'black people' and the negative words, as fast as possible, with as few errors as possible." As for the Incongruent Task, "black people" and "white people" were switched each other. 


\subsection{Results}

Implicit association difference scores. The Implicit Association Difference score (IAD) was calculated with the following equation: IAD $=$ (Number of items completed in the incongruent task) - (Number of items completed in the congruent task). The results showed that the IADs of "black/white people" and "Sambo/Heidi" were negative, revealing that the participants had relatively negative implicit attitudes toward "black people" and "Sambo," but with different magnitudes among the three age groups (see Table 1). Meanwhile, the IADs of "black/white hair" were neutral in two younger groups but positive in the older adult group, showing that the older adults had a relatively favorable implicit attitude toward "black hair." As hypothesized in the introduction, this result also demonstrated that the participants processed the combined words as unified concepts rather than responding separately to each of the Chinese characters.

A two-way ( 3 Age $\times 3$ Target) mixed ANOVA revealed a significant interaction of Age and Target $\left(F_{(4,435)}=7.53, p<0.01, \eta^{2}=0.05\right)$ and a significant main effect of Target $\left(F_{(2,435)}=66.65, p<0.001, \eta^{2}=0.20\right)$ but no significant main effect of Age $\left(F_{(2,435)}=1.90, \mathrm{~ns}\right.$.). The multiple comparisons using the $L S D$ procedure showed that the IADs of older and younger adults were significantly more negative toward "black people" than junior high school students $(L S D=2.75$, $M S e=47.55, p<0.05)$. Additionally, older adults showed higher positive IAD for "black hair" than younger adults and junior high school students $(L S D=$ 2.68, $M S e=45.04, p<0.05)$. There were no statistical age differences among the IADs for "Sambo/Heidi."

Reading experience of LBS. Fifty of 52 older adults and 48 of 49 younger adults answered that they had read $L B S$, while only 18 of 47 junior high school students had read the book. Among the 47 junior high school students 18 students (eight boys and ten girls) had read $L B S$ and 29 (13 boys and 16 girls) had not. It should be noted here that the present study happened to be conducted about 14 years after the LBS books were pulled out of all Japanese bookstores. The undergraduate and adult participants were five years old or older when the books disappeared, but they had read them in their preschool years because almost all kindergartens in Japan had possessed the book. Meanwhile, the junior high school students were one-year-old or younger at that time. Therefore, only those who happened to have the book at home had had the chance to read it.

Table 1. Average implicit association difference scores of three age groups for the target pairs of words.

\begin{tabular}{cccc}
\hline Targets & $\begin{array}{c}\text { Junior high students } \\
(\mathrm{N}=47)\end{array}$ & $\begin{array}{c}\text { Undergraduates } \\
(\mathrm{N}=49)\end{array}$ & $\begin{array}{c}\text { Adults } \\
(\mathrm{N}=52)\end{array}$ \\
\hline Black/White People & $-3.4(6.6)$ & $-7.8(7.1)$ & $-9.4(6.7)$ \\
Sambo/Heidi & $-3.0(4.8)$ & $-2.2(5.7)$ & $-3.6(6.0)$ \\
Black/White Hair & $0.6(5.7)$ & $-0.1(8.5)$ & $3.0(5.4)$ \\
\hline
\end{tabular}

The standard deviations are shown in parentheses. 


\subsection{Post Hoc Analyses of the Reading Effects of $L B S$ on Their Attitudes}

The difference in the reading experiences of $L B S$ could be used for a quasi-experiment to examine the reading effect on the racial discrimination. Table 2 shows the average IADs of the two target pairs, "black/white people" and "Sambo/Heidi" for the two groups, those who had read $L B S$ and had not. For both targets, IADs were negative with small differences. The results of a two-way mixed (2 Reading experiences $\times 2$ Targets) ANOVA revealed no statistical differences either the main effects $\left(F_{(1,90)}=0.39\right.$ and 0.00 , ns., respectively) or the interaction $\left(F_{(1,90)}=1.28, \mathrm{~ns}\right.$. $)$. The post hoc power analysis showed the power of the present comparison with the total of 47 participants assuming the large effect $(f=0.40)$ was only 0.466 (Faul, Erdfelder, Buchner, \& Lang, 2009) [18]. It would have needed 104 participants to attain the power of $\beta=0.8$.

\section{Single-Target Assessment of Implicit Attitude toward "Black People" and "White People"}

All three age groups of the Japanese participants showed an implicit preference for "white people" over "black people." The results could be interpreted to mean that Japanese people had similar implicit attitudes as the American white participants in Greenwald et al. (1998) [9] toward the black people despite the large difference between Japan and the US in the immigration history of the black people. The similar racial attitudes of Japanese people toward black people might have been transplanted into Japanese culture through the US media such as the Hollywood movies and the American TV programs imported into Japan (Lash, 1991) [19].

However, it should be noted that the negative results were only relative. The fact that the reaction times were longer for the incongruent tasks than the congruent tasks only showed the relative implicit preference of "white people" over "black people" among the Japanese participants. It was well known that Caucasians frequently appear in the Japanese commercial advertisements for delivering a good image (Creighton, 1995; Prieler, 2010) [20] [21]. The present results might only reflect the strong preference for white people over black people in Japan. Whether Japanese people had a positive or negative image of black people was not properly assessed by the double-target assessment procedures used. It could reveal only the differences rather than the absolute values. Since it was possible to conduct the single-target procedure using the paper-based IAT, we conducted supplemental assessments for the implicit attitudes toward the black

Table 2. The average IADs of those who had read $L B S$ and had not.

\begin{tabular}{ccc}
\hline Targets & Read $L B S(\mathrm{~N}=18)$ & Not read $L B S(\mathrm{~N}=29)$ \\
\hline Black/White People & $-2.5(7.3)$ & $-3.9(6.1)$ \\
Sambo/Heidi & $-3.6(4.6)$ & $-2.6(4.8)$ \\
\hline
\end{tabular}

The standard deviations are shown in parentheses. 
and white people.

\subsection{Method}

Participants. Thirty-four undergraduates (15 males and 19 females, 20 - 23 years old) and 33 high school students (12 males and 21 females, 16 - 17 years old) participated in this single-target assessment study. The undergraduates participated in the assessment as a part of course requirements. All were native Japanese, who had not participated in the double-target assessments reported above.

Construction of the single-target paper-based IAT. In the single-target IAT, only one of the target words, "white people" or "black people," was interspersed among the evaluation words. Accordingly, the incongruent and congruent tasks were renamed as the positive and negative tasks, respectively. It is worth noting here that the incongruent and congruent tasks did not correspond to the positive and negative tasks in a simple way. The incongruent task was a combination of the positive task of the black target and the negative task of the white target, and the congruent task was a combination of the other two tasks in the other way around.

Procedure. The two single-target versions of IAT were administered to the same participants at the beginning (the white version) and the end (the black version) of an ordinary 90-minute class for undergraduates. The reversed order with about 30 minutes interval was taken for the high school students who participated in a one-day-university class (45-minutes) held at their high school. For both the white and black versions, the three tasks were administered in the same order to the two participant groups, concepts-only, positive, and negative tasks. The positive task was the one in which the participants were asked to draw a circle on each of the targets as well as the other pleasant words in 30 seconds. As for the negative task, the participants were instructed to draw a cross on each of the targets in 30 seconds. The standard informed-consent procedure was taken by claiming them that the tests would reveal their implicit attitudes and that they could stop participating any time they wished to do so. All participants voluntarily participated in the study without quitting.

\subsection{Results}

Implicit association scores. Instead of the IAD, the new index, the Implicit Association Score (IAS), was calculated using the following equation: IAS $=$ (Number of items completed on the positive task) - (Number of items completed on the negative task). The IAS became a positive value if the target was implicitly associated more strongly with pleasant concepts or a negative if associated more strongly with unpleasant concepts.

The average IASs for "white people" and "black people" were both positive with different magnitudes (cf., Table 3). The results indicated that both age groups performed similarly better on the positive tasks when the target was "white people," revealing that they tended to have a strongly favorable image for 
Table 3. The average implicit association scores measured separately using the single-target procedure.

\begin{tabular}{ccc}
\hline Targets & Undergraduates $(\mathrm{N}=34)$ & High school students $(\mathrm{N}=33)$ \\
\hline Black people & $2.1(6.4)$ & $0.3(5.3)$ \\
White people & $4.1(5.7)$ & $3.8(7.0)$ \\
\hline
\end{tabular}

The standard deviations are shown in parentheses.

white people (cf., Creighton, 1995; Prieler, 2010) [20] [21]. It should be pointed out that the average IASs for "black people" were also positive, but of a much smaller magnitude. It showed that the Japanese participants performed quicker on the positive task than on the negative task even when the target was "black people." This result is particularly noteworthy because it implies that the negative IADs obtained from the "black/white people" targets in the double-target assessment only resulted from the differences between the positive IASs of "white people" and "black people."

\section{Discussion}

\subsection{Racial Attitudes toward Blacks and $L B S$ among Japanese People}

The present study revealed that Japanese people throughout three age groups possessed more negative implicit images of black people and Sambo than white people and Heidi. As Russell (1991) [3] pointed out, there was a hidden tendency of discriminating black people among Japanese people even if they consciously denied it. However, the finding of the supplementary study showed that Japanese people had a positive implicit image of black people when assessed with the single-target IAT. The relatively negative images of black people were only the shades of overly positive images of white people among Japanese people, as having been argued by many researchers (Creighton, 1995; Prieler, 2010) [20] [21].

These findings showed us the need for separate implicit assessments of the racial attitude toward each racial and ethnic group rather than assessing the relative preference between two groups. Greenwald et al. (1998) [9] reported the results of the Japanese/Korean Americans who assessed Japanese/Korean names in the IAT tasks. Japanese Americans showed more positive IAT scores on the Japanese names than Korean names and vice versa. However, it did not mean Japanese Americans had a negative attitude toward Koreans or Korean Americans toward Japanese. They might have had positive attitudes with different valences from each other. It is desirable to use the single category version of IAT (Karpinski \& Steinman, 2006) [22], or the single-target paper-based IAT as used in this study, to re-examine the Greenwald et al. results.

\subsection{Reading Experience of $L B S$ and Its Effects on the Implicit Attitude toward Blacks}

Russell (1991) [3] argued that one of the reasons $L B S$ was not appropriate for a 
children's book was that it would develop a racist attitude against blacks. However, the results of the post hoc analysis showed that the reading experience of LBS did not have the alleged effect on the racial attitude of junior high school students. Although it was not based on a fully randomized controlled design with a sufficient statistical power, the present result would lend support for the argument that it was excessive concern that $L B S$ might develop a racial prejudice in young readers.

Mori (2005) [1] compared the original LBS story and a non-racist version (Mori, 1997) [23], in which a new protagonist, a black Labrador puppy named "Little Black" appeared instead of a black boy named "Sambo." The two stories were read to preschool children and their preferences were ascertained. The results showed no difference between the two versions in terms of entertainment. Not like the present study, the sample size of Mori (2005) [1] was sufficient to support the negative finding at $\beta>0.8$ level. Mori (2005) [1] concluded that although the word "Sambo" had had a misfortunate historical background, the story of the book itself was free from a racist implication.

As stated above, the book was accused of the concern that the book would develop a racist attitude against blacks (Russell, 1991) [3]. Still, we have lacked sufficient evidence yet for proving or disproving the concern. However, the present study, as well as Mori (2005) [1], threw a considerable doubt against the concern. We would rather suspect it an excessive and imaginary fear. It was unfortunate that Iwanami Publishing and other publishers in Japan withdrew their versions of $L B S$ from the bookstores throughout Japan in 1988. However, $L B S$ came back in a revised version in Japan in 1997 (M. Mori, 1997; Barton, 1998) [1] [24]. Now, a variety of versions are available in Japan (cf., Todayama, 2007; Mori, 2014) [2] [25].

\subsection{Limitations and Remaining Issues}

By utilizing an implicit measure, the present study successfully revealed the hidden discriminative tendencies of Japanese people against black people and Sambo. Most Japanese people may publicly deny their racist attitude in a questionnaire, but an implicit measure can probe the hidden minds and reveal them. The single-target assessment of IAT also revealed an interesting result; the negative implicit images of black people in Japanese people might have resulted from the fact that Japanese people have excessive positive images of white people. It was an agreeable finding that Japanese students had a positive implicit image of black people when assessed separately from the image of white people.

The present findings may mean that Japanese people do not hate black people but they discriminate them. We should not accept racism as well as discrimination. We should not hate others in different ethnicities and cultures. But, would it be allowed to admire other ethnic groups excessively? What if an admiration of one ethnic group would result in a relative disrespect of other groups? We would like to leave this issue to studies with broader background since it is too 
large to be treated in this assessment study. The issues of racism and discrimination are difficult to tackle but what we need is to accumulate objective evidence. The present study demonstrated that the paper-based IAT would be a useful tool for such studies.

\section{Conclusion}

The present study showed that Japanese people possessed more negative implicit images of black people and Sambo than white people and Heidi. However, the negative scores of black people were only relative as compared with highly positive scores of white people among Japanese people. Being measured with the single-target IAT, they were positive by themselves. Although it was not a randomized-controlled experiment, the post hoc analysis on the effect of reading $L B S$ on the racial attitude disproved the concerns that the book might develop a racial prejudice.

\section{Acknowledgements}

The author would like to express his thanks to all the participants who voluntarily participated in this research. Hiromi Ikegami collected the data in the double-target assessment study for her graduation thesis submitted to Shinshu University in 2003 under the supervision of the present author. The paper-based IAT used in this study was a prototype of those reported in Mori, Uchida, and Imada (2008) [14].

\section{Declaration of Conflicting Interests}

This research was supported by a Grant-in-Aid from the Japanese Ministry of Education, Culture, Sports, Science, and Technology (KAKENHI Grant No. 13610081) while the author was at Shinshu University, Nagano, Japan. There were no conflicts of interest concerning the present research.

\section{References}

[1] Mori, K. (2005) A Comparison of Amusingness for Japanese Children and Senior Citizens of The Story of Little Black Sambo in the Traditional Version and a Nonracist Version. Social Behavior and Personality, 33, 455-466. https://doi.org/10.2224/sbp.2005.33.5.455

[2] Mori, K. (2014) A Revival of Little Black Sambo in Japan. Advances in Literary Study, 2, 9-11. https://doi.org/10.4236/als.2014.21003

[3] Russell, J. (1991) Race and Reflexivity: The Black Other in Contemporary Japanese Mass Culture. Cultural Anthropology, 6, 3-25.

[4] Sircar, S. (2004) Little Brown Sanjay and Little Black Sambo: Childhood Reading, Adult Rereading; Colonial Text and Postcolonial Reception. The Lion and the Unicorn, 28, 131-156. https://doi.org/10.1353/uni.2004.0013

[5] Tajima, A. and Thornton. M. (2012) Strategic Solidarity: Japanese Imaginings of Blacks and Race in Popular Media. Inter-Asia Cultural Studies, 13, 345-364. https://doi.org/10.1080/14649373.2012.689690 
[6] DeMaio, T.J. (1984) Social Desirability and Survey Measurement: A Review. In: Turner, C.F. and Martin, E., Eds., Surveying Subjective Phenomena, Vol. 2, Russell Sage Foundation, New York, NY, 257-281.

[7] Greenwald, A.G. and Banaji, M.R. (1995) Implicit Social Cognition: Attitudes, Self-Esteem, and Stereotypes. Psychological Review, 102, 4-27.

https://doi.org/10.1037/0033-295X.102.1.4

[8] Fazio, R.H., Jackson, J.R., Dunton, B.C. and Williams, C.J. (1995) Variability in Automatic Activation as an Unobtrusive Measure of Racial Attitudes: A Bona Fide Pipeline? Journal of Personality and Social Psychology, 69, 1013-1027. https://doi.org/10.1037/0022-3514.69.6.1013

[9] Greenwald, A.G., McGhee, D.E. and Schwartz, J.L.K. (1998) Measuring Individual Differences in Implicit Cognition: The Implicit Association Test. Journal of Personality and Social Psychology, 74, 1464-1480. https://doi.org/10.1037/0022-3514.74.6.1464

[10] Wittenbrink, B., Judd, C. and Park, B. (1997) Evidence for Racial Prejudice at the Implicit Level and Its Relationship with Questionnaire Measures. Journal of Personality and Social Psychology, 72, 262-274. https://doi.org/10.1037/0022-3514.72.2.262

[11] McConnell, A.R. and Leibold, J.M. (2001) Relations among the Implicit Association Test, Discriminatory Behavior, and explicit measures of racial attitudes. Journal of Experimental Social Psychology, 37, 435-442. https://doi.org/10.1006/jesp.2000.1470

[12] Lemm, K.M., Lane, K.A., Sattler, D.N., Khan, S.R. and Nosek, B.A. (2008) Assessing Implicit Cognitions with a Paper-Format Implicit Association Test. In: Morrison, M.A. and Morrison, T.G., Eds., The Psychology of Modern Prejudice, Hauppauge, Nova Science Publishers, New York, 121-146.

[13] Lowery, B.S., Hardin, C.D. and Sinclair, S. (2001) Social Influence Effects on Automatic Racial Prejudice. Journal of Personality and Social Psychology, 81, 842-855. https://doi.org/10.1037/0022-3514.81.5.842

[14] Mori, K., Uchida, A. and Imada, R. (2008) A Paper-Format Group Performance Test for Measuring the Implicit Association of Target Concepts. Behavior Research Methods, 40, 546-555. https://doi.org/10.3758/BRM.40.2.546

[15] Teachman, B.A., Gapinski, K.D., Brownell, K.D., Rawlins, M. and Jeyaram, S. (2003) Demonstrations of Implicit Anti-Fat Bias: The Impact of Providing Causal Information and Evoking Empathy. Health Psychology, 22, 68-78. https://doi.org/10.1037/0278-6133.22.1.68

[16] Vargas, P.T., Sekaquaptewa, D. and von Hippel, W. (2007) Armed Only with Paper and Pencil: "Low-Tech" Measures of Implicit Attitudes. In: Wittenbrink, B. and Schwarz, N., Eds., Implicit Measures of Attitudes, Guilford Press, New York, 103-124.

[17] Nakayama, M., Sears, C.R., Hino, Y. and Lupker, S.J. (2014) Do Masked Orthographic Neighbor Primes Facilitate or Inhibit the Processing of Kanji Compound Words? Journal of Experimental Psychology: Human Perception and Performance, 40, 813-840. https://doi.org/10.1037/a0035112

[18] Faul, F., Erdfelder, E., Buchner, A. and Lang, A.-G. (2009) Statistical Power Analyses using G Power 3.1: Tests for Correlation and Regression Analyses. Behavior Research Methods, 41, 1149-1160. https://doi.org/10.3758/BRM.41.4.1149

[19] Lash III, W.H. (1991) Unwelcome Imports: Racism, Sexism, and Foreign Invest- 
ment. Michigan Journal of International Law, 13, 4-9. http://www.mjilonline.org/

[20] Creighton, M.R. (1995) Imaging the Other in Japanese Advertising Campaigns. In: Carrier, J., Ed., Occidentalism: Images of the West, Clarendon Press, Oxford, 135-160.

[21] Prieler, M. (2010) Othering, Racial Hierarchies and Identity Construction in Japanese Television Advertising. International Journal of Cultural Studies, 13, 511-529. https://doi.org/10.1177/1367877910372709

[22] Karpinski, A. and Steinman, R.B. (2006) The Single Category Implicit Association Test as a Measure of Implicit Social Cognition. Journal of Personality and Social Psychology, 91, 16-32. https://doi.org/10.1037/0022-3514.91.1.16

[23] Mori, M. (1997) Chibikuro Sampo [The Story of Little Black Taking a Walk]. Kitaooji Shobo Publishing, Kyoto.

[24] Barton, P.S. (1998) Pictus Orbis Sambo: A Publishing History, Checklist and Price Guide for the Story of Little Black Sambo (1899-1999). Pictus Orbis Press, Sun City.

[25] Todayama, M. (2007) Revival of an Old Image: The Story of Little Black Sambo in Japan. Bookbird: A Journal of International Children's Literature, 45, 23-30. http://www.ibby.org/index.php?id=1035 